Authors' Pre-publication version

Full citation:

Hockey, J and Allen-Collinson, J (2006) Seeing the way: visual sociology and the distance runner's perspective, Visual Studies. Journal of the International Visual Sociology Association, 21 (1): 70-81. 1472-586X

\title{
Seeing the way: visual sociology and the distance runner's perspective
}

2006

\author{
John Hockey \\ Jacquelyn Allen Collinson
}




\section{Seeing the way: visual sociology and the distance runner's perspective}

Abstract

Employing visual and autoethnographic data from a 2-year research project on distance runners, this paper seeks to examine the activity of seeing in relation to the activity of distance running. One of the methodological aims of the paper is to develop the linkage between visual and autoethnographic data in combining an observation-based narrative and sociological analysis with photographs. This combination aims to convey to the reader not only some of the specific subcultural knowledge and particular ways of seeing, but also something of the runner's embodied feelings and experience of momentum en route. Via the combination of narrative and photographs we seek a more effective way of communicating just how distance runners see and experience their training terrain. The importance of subjecting to detailed sociological analysis mundane, everyday practices has been highlighted by many, including those of an ethnomethodological perspective. Indeed, without the competence of social actors in accomplishing these mundane, routine understandings and practices, it is argued, there would in fact be no social order. 


\section{Introduction}

Employing visual and autoethnographic data from a 2-year project on distance runners, this paper seeks to mark the activity of seeing in relation to the activity of distance running. Such forms of mundane activity pervade social life generally but as Brekhus (1998: 36) has noted, much of it remains 'unmarked' by social researchers, and consequently remains largely 'unnamed and unaccented'. As Knowles and Sweetman (2004: 7) advocate, we need to make use of the capacity of visual images 'to reveal what is hidden in the inner mechanisms of the ordinary and the taken for granted'. Following Harper (2004: 93), in this paper we construct a Gestalt combining the visual with an observation-based narrative and sociological analysis, presenting to the reader 'more than the modes of analysis offer separately'. One of the methodological aims of this paper is to develop the linkage between visual and ethnographic (or in this case autoethnographic) data; a connection long ago advocated by Becker $(1974,1995)$.

\section{The Mundane}

The ways in which people walk, drive to work, take the lift, ask for directions, or take the dog for a walk - these are the kind of repetitive, public, social patterns which constitute much mundane activity and have all too often been taken for granted by sociologists (and others), leaving them unproblematised and under-analysed. Ethnomethodologists in particular have signalled the importance of subjecting to detailed analysis the mundane, everyday practices of social life and the competence of social actors in accomplishing these, without which, it is argued, there would in fact be no social order (Rustin 1993). This paper seeks to address a lacuna in the literature by analysing in this way a specific, mundane social practice, that of distance running, and in particular the ways of seeing which are utilised in the accomplishment of training for distance running. 
Competing in middle/long-distance races, or indeed even running the required distances, necessitates a considerable volume of daily training, and runners' energy and time commitment to training runs far exceeds their involvement in racing. Training constitutes a central, habitual and mundane activity within the distance runner's world; mundane in its regularity and routinized nature, but also transcending it, as for many runners and other sports participants sport in some ways represents an 'escape' from the mundane (Segrave 2000). A crucial component of such habitual training activity is the evaluation of the environment within which it takes place, for it is via such interpretive activity that lines of individual action and subsequently social interaction take place.

For most of us, the context which surrounds us as social actors is evaluated and interpreted using broad cultural codes (Rose 1993: 89); we see in a particular way, using cultural resources. Furthermore, specific social groups employ distinctive 'ways of seeing': for example, the ways in which women see public places (Brooks Gardner 1980; Lofland 1973), or how different occupational groups view their work situations. Thus, police have a particular vision of the beat they patrol (Bittner 1967), airport workers see airplanes in a particular task-relevant way (Goodwin and Goodwin 1998), and infantrymen have a specific way of seeing the terrain they traverse (Woodward 1998). What is actually seen in these situations is dependent upon the knowledge which has been accumulated via previous experience of the activities themselves. Ways of seeing are structured by specific kinds of knowledge, which are in turn informed by the act of seeing itself, in a complex circular process. As Emmison and Smith (2000: 185) note: 'Environments are not simply places where we see things in a passive way. They are also locations where we must look in active ways.' This active looking is necessary in order to accomplish the particular task(s) at hand. Through the embodied running of particular sequences of social space, training routes are constructed (Psathas 1979; Carr et al. 1992) and are dependent 
upon a specific, active way of seeing; each route forming part of an architecture of memory (Donald 1995).

The analysis of a specific way of seeing forms the focus of this paper. Indeed, the importance of this kind of seeing should not be underestimated, for it is via the interpretative activity which forms part of it that situationally-appropriate behaviour occurs and mundane activities are accomplished, which themselves provide the foundations for wider social patterns (Hemmings et al 2002). The principal theoretical approach selected in order to analyse these activities and underpinning knowledge will now be considered.

\section{Ethnomethodology}

The theoretical perspective employed here derives primarily from the phenomenology of Alfred Schutz (1967), elements of which focus upon the ways in which individuals construct and manage routine social life using a 'stock of knowledge at hand', constituted of sedimentations of previous experience, permitting them to make sense of particular contexts. The great epistemological problem for Schutz was discovering how such common-sense understanding is possible. In his formulation, common-sense knowledge is constituted of typfications, the commonsense constructs which individuals use to order the social world on a moment-tomoment basis, and which: 'organize our impressions, at the start, into objects, events, and categories and so structure our experience' (Benson and Hughes, 1983: 53). Such typifications are generally taken for granted in the normal, everyday scheme of things; for the most part they are tacitly held and operationalised, and 'marking' them is one of the tasks facing researchers within this tradition. This paper seeks to mark the practical activity of seeing, from the particular perspective of a middle/distance-runner. 
In applying Schutzian insights to the study of members' methods for producing everyday social order, Harold Garfinkel (1967) developed ethnomethodology, the study of 'the common-sense reasoning skills and abilities through which ordinary members of a culture produce and recognize intelligible courses of action (Heritage, 1989: 21), in other words, the processes 'members use to do "going about knowing the world"' (Benson and Hughes, 1983: 56). Ethnomethodologists analyse in detail the precise ways in which social order is constructed and maintained at the microlevel of social interaction, and consequently demand the close empirical examination of the 'detailed and observable practices which make up the incarnate production of ordinary social facts' (Lynch et al, 1983).

Interestingly, whilst ethnomethodological analysis has focussed upon various rulebased 'games' (such as Garfinkel's (1963) consideration of chess, and noughts and crosses), only rarely has it centred upon the actual physical aspects of 'doing' sporting or other physical activities such as walking (see for example: Ryave and Schenkein, 1975; Sudnow, 1978; Kew, 1986; Goode, 1994; Coates, 1999). The following account therefore attempts to contribute to the literature and is based upon data derived from a collective autoethnographic research project, details of which are given below. As Coates (1999: 25) notes: 'To take any physical activity ... and consider how to analyse it, as a form of social action, is to give oneself an analytically demanding task'. Notwithstanding the difficulty of the task, this paper seeks to do precisely that.

Whilst researchers employing ethnomethodological approaches have tended to focus primarily upon linguistic communication, as Emmison and Smith (2000) note, ethnomethodological principles can be equally well illustrated in the examination of visual data. Sharrock and Anderson, for example, analysed directional signs in a medical school, noting that "the business of "reading signs" is an embedded activity 
... (which) involves a highly particularized and localized kind of work' (1979: 90).

'Reading' a running route requires of runners analogous work, based upon a highly particularized and localized form of 'route knowledge'. Before proceeding to consider the methods we used to uncover these ways of seeing, brief details of the autoethnographic research approach follow.

\section{Autoethnography}

In common with its ethnographic parent, autoethnography is a research strategy which underpins the use and selection of specific methods in order to approach certain research questions. Over the last two decades, autoethnography has gained more widespread usage and acceptance within sections of the sociological and anthropological communities (see for example: Hayano 1979; Ellis 1997; ReedDanahay 1997; van Maanen 1995; Coffey 1999; Sparkes 2000). Debates continue, however, over the appropriateness of the terminology, and a whole panoply of other terms co-exists, for example, self-narratives, récits de soi/moi, personal narratives, ethnographic autobiography (see Ellis and Bochner 2000: 739 for a detailed listing).

Whilst bearing in mind these debates, for the purposes of this article the term 'autoethnography' will be used. This has been defined as an autobiographical genre of writing and research (Ellis and Bochner 2000: 739), focussing upon the dialectics of subjectivity and culture. Autoethnographers constitute a somewhat heterogeneous group of researchers and vary widely in the primacy of their focus, whether on the research process (graphy), culture (ethnos) or self (auto) (Ellis and Bochner 2000). In general, however, autoethnography involves the detailed analysis of oneself qua member of a social group, for example as a card-player (Hayano 1982), swimmer (Rinehart 1998) or distance runner (Denison 2002; Allen Collinson and Hockey 2001). The distinctiveness of autoethnography as an ethnographic research process lies in its efforts to combine detailed fieldnotes with 'headnotes' 
(Sanjek 1990), the researcher's actual experience of engaging with the phenomena at hand. The self and the ethnographic field are symbiotic, and in effect this combination forms the pivot of analysis (Coffey 1999). In addition, autoethnographers seek explicitly to 'write themselves in' to their accounts of fieldwork in a rigorous, analytic fashion. There exists a plurality of autoethnographic methods to gather and analyse research data, including: personal diaries/logs, photographs, video and audio recordings, and field notes gathered by participant observation. Our data collection methods are described below along with brief details of the biographical context. We sought to combine narrative and photography in the production of an autoethnographic account. This approach has been utilised within anthropology (Okely 1996: 147-174) and also has links with other methods of visual research such as autophotography (Spence 1986; Harrison 2002).

\section{Fieldwork}

So as better to situate the analysis which follows, brief biographical information about the authors is required. For the last 18 years both of us have undertaken distance running training together, for 6 or 7 days a week, sometimes twice a day. With a background in athletics which has involved racing distances from the marathon to five miles, our involvement in this sport now stretches back 19 and 38 years respectively. At the ages of 45 and 59 respectively, under the UK system we are categorised as 'veteran' runners. We have consequently developed an extensive base of insider knowledge of the activity. The background to this particular research project is as follows.

In 1997, during a week of post-work, dark, winter training, knee injuries befell both of us. These injuries were not the usual strains or pains which athletes habitually endure, indeed the seriousness of them propelled us into instigating a research project which involved the systematic documentation of our responses to the injuries 
(Allen Collinson 2003; Hockey 2005) and the subsequent rehabilitative period which stretched over a period of two years. The data collection methods we utilised were individual field notes and micro-tape recordings which were transcribed into two individual research diaries or logs. We subsequently interrogated and analysed these logs via a method somewhat akin to the constant comparative method (Glaser and Strauss 1967), but to a less formalised degree. On the basis of this, we created a third collaborative log that contained analytic themes and concepts found in our data. A 'bonus' to the data collection process was that when walking our daily training routes as part of our remedial activity, we became aware of a previously taken for granted stock of knowledge. This knowledge was pushed to the fore in the process of articulating our thoughts about the routes. Previously, when concentrating on actually running the routes, we had not spoken this information to each other, and yet it proved to be crucial to successful traversing of the training terrain.

\section{Portraying the Data}

In order to portray the kinds of visual practices distance runners use in order to accomplish training in an effective manner, the following section consists of a narrative depiction of one part of a favourite training route, and is based upon our field notes. The narrative itself portrays knowledge about that route, for, as others have noted, runners often build up extensive and detailed knowledge of their training routes (Smith 1997; Lutz 1991). This knowledge also constructs how the route is seen in the process of running. Simultaneously, the knowledge possessed and the vision deployed as a consequence of it impact upon the corporeal movement of running itself, for as Crossley (1995: 47) notes, mind is intimately linked to body. The runner's body adjusts to what is seen and understood as s/he moves over the training route. 
In the narrative, the route is presented as an exemplar in order to illustrate many of the particular categories of knowledge which inform our way of seeing; knowledge utilised not only on this specific route, but also on other running routes. When faced with constructing the narrative on the basis of our field notes, in congruence with the autoethnographic enterprise, we chose to produce an account which invoked a subjective experience, particularly that of momentum, and hopefully conveys to the reader some of the knowledge, vision and also the embodied feelings experienced en route. By employing the present tense and first person singular, we also aim to convey an 'immediacy' (Sparkes 2000), and the feeling that one runner is actually traversing the route. In reality, the field notes in which the narrative is grounded constitute a joint resource, shared by both authors, not only as a sociological record but also experientially. Hence, both the narrative and the ' $l$ ' within it are effectively an amalgamation of shared knowledge of a training route.

Accompanying the narrative are a number of photographs which alone cannot of course impart the route knowledge. The narrative can impart something of this knowledge, but it is hoped that the combination of narrative and photographs provides a more effective way of communicating to the reader how distance runners see their training terrain. The photographs were selected so as to depict various kinds of terrain and the sorts of running concerns associated with them. Interestingly, many of the photographs we originally took had to be discarded as they failed to demonstrate visually the elements of the route we were trying to capture, for example uneven, rutted ground; a limitation of the photographic method or the photographer perhaps! The photographs we did select are hopefully rendered meaningful via some of the subcultural discourses (Pink 2001: 51) of distance running. In the absence of such commentary - provided in the narrative and the subsequent discussion - the photographs per se would be devoid of the particular set of distance-running meanings. Indeed, without that particular cultural 
contextualisation, one sees merely bits of ground, parkland, pavement, trees, and so on. Only when the particular subcultural stock of knowledge is used to 'frame' (Goffman 1974, Snow et al 1986) the photographs, does the distance runner's specific way of seeing become accessible to the reader/observer.

The narrative begins...

\section{Seeing the Route}

I get out of the car with my legs all stiff after a day at the work desk, look at the watch: 1745 hours, time to go and put some miles in. Later, I check the lacing on my running shoes, hitch up my training tights and start to jog onto the park. In a few yards I move off the grass on to a path, feeling its newly laid bitumen easy on my feet, heading for some ornamental gates. Cautiously, I slow down, knowing that with the narrowing of the path as it reaches the gates I am liable to encounter some combination of: parents with prams, mountain bikers with attitude, psychotic pets and deranged children, all with the capacity to shoot into my path and do me damage!

\section{Insert Figure 1 about here}

Negotiating the gates a slope unfolds before me, and I head up it, taking a line between two fir trees, selecting where the grass is most even and thus better for maintaining momentum. Leaning forward, shortening my stride, arms working. Just before the top I cut left between two bushes and my eyes focus directly on my feet as I point my toes so as to minimize the contact of my feet with the ground. Intently scanning what is around me, looking to avoid the cast-off needles routinely left by local narcotic addicts. Down the slope and I avoid the central path as I know and can see the usual heaps of 
dog crap decoration. Strange why dog owners always seem to get their pets to 'do it' in certain areas, and who wants toxic rubbish on your shoes, and then on your hands and a month off training with some vicious bug!

Back through the gates and a sharp left down the narrow gloomy underpass which connects the other half of the park, a subway for idiot mad cyclists, unsupervised dogs and toddlers; together meaning reduced pace, trying to see to place my feet. At certain times of the year inebriated hordes returning from the race course empty their bladders from a balustrade above, vocally caricaturing my running frame as that of an 'AIDS victim' (cf. Smith 1997).

\section{Insert Figures 2 \& 3 about here}

Into the other park and up a little pitch, shortening the stride, working the quadriceps harder, hamstrings contracting sharply and grumbling, moving right all the time to avoid a marshy patch there for six months of the year, work the arms, murmuring 'come on dig in a bit'. A bigger slope is before me, up the grass past the tennis courts, smooth all over now, any line taken will do.

\section{Insert Figure 4 about here}

Good for doing hill repeats here, much to the consternation of those languidly playing tennis! Along the park-top, going good, summer hazard arises due to mini golf - be aware! Reach a big clump of trees around which in winter is a boggy morass, producing freezing, sodden shoes, and sore Achilles' tendons as one's heels get sucked down too far in the mud. In 
summer there are great hardened ruts which do nothing for shin muscles which can get inflamed all too easily.

\section{Insert Figure 5 about here}

I take a big swing to the left, knowing a smoother, drier and more cushioned line. The ground slopes down and as the park opens I raise the pace, keeping to the left, because over to the right the terrain displays the same seasonal characteristics as around the clump of trees. Maintaining the same pace, moving up the park I pass over various putting greens, nice to the feet, but in the winter dark, poorly-lit by distant street lighting, the exact position of each hole being riveted into my visual cortex by visions of past ankle injuries. Across the park's dividing road and down to its perimeter under which a stream flows, making it much colder on winter evenings, and when running here an extra layer goes on the legs. Two to three times a week on dark nights I can run here, as the local sports stadium floodlights reach this far. Up a short pitch and through a line of trees, remembering the time I tried it when the lights were on only half power, and I ended up being hit by a branch in the chest and couldn't train for a week. "Mind the trees, mind the trees" brain telling feet which skip over roots, accelerating down the line, ducking to avoid low-hanging branches.

\section{Insert Figure 6 about here}

Re-cross the road, down another slope we used to use for repeat speed work intervals until major drainage work transformed it into terrain where one could quite easily smash a leg. Dead Slow. On to the big, flat vista of the park, a long line of trees sought out as shade for the whole run when the high 
summer sun burns my celtic skin - up and down, up and down, monotonous but necessary.

\section{Insert Figure 7 about here}

Now in the autumn, I reject that line covered as it is with pine cones and tree debris. Pine cones are not innocent; they lie in wait for the unwary runner, rolling perilously under the foot with potential injurious consequences. Innocent neither are the multi-coloured piles of leaves concealing kerb edges, roots and other booby-traps. Moving alongside but outside the tree line, keeping the rhythm and the cadence high, lengthening the stride, increasing the pace to accomplish four long efforts. Mouth dry and gasping, I look with suspicion at the autumnal offerings fallen from trees.

Making a right turn to the end of the park alongside the football pitches, slowing my momentum as I know minor drainage work was also done here, and re-turfing was inadequate. The grass has grown over divots and holes and I know ambushes await for the naive runner! Circling slowly I look back down the park to the basketball court area, adjacent to the path where dog owners let their carnivorous charges roam with almost routine negative consequences for athletic legs (cf. Smith 1997). Also, it is from this area that during high summer teenagers illegally ride off-road motorcycles, occasionally for fun, aiming them at one's lightly-clad torso. Today, luckily there are none of these obstacles to distract my training.

\section{Insert Figure 8 about here}


Taking the back gate out of the park I run along a pavement, dimly lit in the winter gloom, and in places deformed by badly laid slabs which bruise the toes, so I opt for a line on the right hand edge, for here there have been recent repairs, and the surface flows with my feet's momentum. Picking the legs up now, but still keeping the speed in check until I pass the concealed entrance of house, out of which one dark night a car screeched without warning, leaving me in mid-stride on its bonnet, and the driver with a near heart attack; 'careful' ringing in my mind as I pass by.

Crossing a major road, I smile when reaching the park again, for the next strip of flat terrain is great, even in a hot summer the grass has some resilience, keeping its smoothness and there are no hidden surprises, one can really do fast intervals here.

\section{Insert Figure 9 about here}

I increase the cadence, and summer shifts to winter and I can still do them thanks to the street lighting and it's never too wet to get decent traction. On to the toes, inclining the torso and head, the rasping of the breath as the effort hits the lungs, half a dozen striding repetitions up and down, feeling the chill dew seeping through my feet.

Crossing a small junction, another flat smooth stretch of park appears to beckon on its far side, or at least it was smooth and for a number of years we did real speedwork on it, lots of repetitions. Unfortunately, a series of fairs and unofficial football games have now generated lots of concealed ruts and divots. Although I can lengthen my stride here real fast work is not to be 
recommended - hit one of those divots at speed and a injury is on the cards. The natural history of some parkland then, once seen in one way and now another...

I leave the park, stride down a minor road and cross a roundabout with a large grass area at its centre, my feet feeling the difference as the concreteinduced jarring subsides. I know the grass is smooth at this point and there is enough reflection from the street lights so that I can traverse it safely, even in the darkest winter nights, if I weave artfully between the shadows. Crossing the last major road on my route I crank up my awareness, as experience has told me that when fatigue sets in alertness is diminished. Cars hurtle precipitously around the roundabout and sometimes I wonder whether centrifugal forces will be sufficient to keep them on-road - and off me!

\section{Insert Figure 10 about here}

On to the far pavement and past the big lilac tree which when flowering causes me to hold my breath for some yards, to prevent hay fever going crazy, running is hard enough without that kind of irritation. Careful now not to stumble over tarmac-packed roots, with potential ankle-wrenching consequences.

\section{Insert Figure 11 about here}

Around the corner on a narrow, curved pavement with its slope of 45 degrees right down to left, listening for the traffic coming from behind. Reversing the route and starting with this section means my old Achilles' tendons hate the angle, but it's either that or a potential visit to the Accident 
\& Emergency department of the local hospital! I look down the street to my house, my legs and back moist, pleased that for today at least the running body, mind and eye, have done what they are supposed to.

\section{Discussion}

In order to contextualise the above narrative, it is necessary to portray and analyse something of the particular stock of knowledge underpinning runners' ways of seeing and thus their methodic practices. The concerns upon which we have chosen to focus relate primarily to safety and performance. The ways in which runners actually look at and check terrain and other features is also salient, and is discussed below, before we proceed to examine some of the typifications employed by runners, and which are encoded in their everyday language.

\section{Safety}

In relation to safety issues, in many ways the runner becomes an 'open person' (Goffman 1963) when training in public places, and unfortunately therefore subject to routine comment, harassment, and on rare occasions assault, from members of the general public (Smith 1997). Runners consequently become acutely aware of particular sites (clubs, pubs, bars, etc) on their running routes, where there is potential risk of such kind of abuse. Along with this kind of potential menace exists another more prevalent threat to runners' well being. This is generated by an amalgam of hazards, for example: cyclists, vehicles and their owners, the canine population, and certain physical features of the running terrain itself. Viewed from the perspective of the runner, this amalgam of features always harbours the potential for provoking athletic injury, with the consequent loss of training and racing time. Within the subculture of distance running, narratives of injury constitute one of the dominant discourses (Howe 2004), and there is a perennial concern to avoid injury when 
training. Hazardous points on the route (busy traffic intersections, hidden driveways, heavily used dog-walking paths, etc) are then identified and categorized by runners. In addition, the biography of each individual runner necessarily influences the kinds of hazard perceived and identified. Sadly, the great majority of experienced distance runners have a past littered with athletic injury and consequently have intimate knowledge of how their moving bodies react to different types of terrain.

\section{Performance}

The second major concern informing the ways in which training routes are seen relates to performance. Runners undertake training to improve their performance so as to be able to race effectively. The kind of terrain runners traverse determines or at least heavily influences, the kind of running which is possible. So for example, flat, smooth road surfaces allow fast, short 'interval' running which runners term 'speed work'. In stark contrast, ploughed fields would discourage this form of training as the terrain is much too difficult to maintain any kind of fast rhythm, and ankles would be liable to injury. Conversely, however, running over difficult terrain at slower paces builds strength and endurance. With these practical concerns in mind, runners become highly attuned and attentive to the nature of terrain and its possibilities for enhancing their performance.

Knowledge regarding the going of the terrain and its 'risk-points' flows from the practical concerns of performance and safety. Furthermore, the known and the seen in relation to routes change temporally. For instance, roads which are typified as bad going at night due to poor lighting conditions, may well be perfectly good during daylight hours. The going over grassy parkland will change as a result of seasonal variations, with consequences for performance and safety, and thus for how it is understood and viewed by runners. Furthermore, the ways in which runners physically run is influenced by that vision, in terms of where they place their feet, how 
they position them: far apart when striding down hill, close together on rough ground, and so on. This in turn changes bodily posture and direction.

\section{Looking}

How runners look at and check terrain and other variables is also of interest to the sociological and ethnomethological eye. Sudnow (1972) has stressed the importance of 'the glance' as a form of visual inquiry, particularly in situations where only glances are possible or permitted. How runners actually see when moving across terrain, especially when rough or badly lit, is usually achieved via a sequence of glances moving from the near foreground (5 metres or so) to the middle ground and back again. Glances to the middle ground become less frequent on particularly problematic sections of route (ploughed fields, deformed pavements etc) as runners visually analyse the ground in a highly focused manner, so as to enhance their own 'going' (a term also applied to the runner as well as the terrain) and avoid injury. In congruence with Psathas' work on the reading of maps, it emerged from the data that our running route is identified as a 'set of sequential particulars' (1979: 224), such as tracts of grassland, sections of road and pavement, roundabouts, an underpass, stretches between markers such as lampposts, to name but a few. Runners in general selectively attend to the features of their running which become 'visible, rational and reportable for all practical purposes' (Garfinkel 1967: vii), in this case, accomplishing training safely and efficiently.

In addition to using the glance to check terrain, when running together we also use it regularly to check and monitor various indications of the other's running form, primarily to ensure that we maintain a similar pace and so achieve running-together. Quick glances at one's training partner(s), are efficient means of gauging facial expression, for example, as a good indicator of the other's 'going' on the run. Frowning, grimaces, tensing of features, sunken eyes, all testify to difficulties and so 
give the observer advance notice to slow down her/his pace either then and there, or at a subsequent point in the training run. Body expressions are checked and monitored in an analogous fashion. For example, the angle of the torso, tenseness of neck, shoulder and arm muscles, all can be used to judge the going of one's partner, as can stumbling, tripping over, and rolling the head more than usual. Accomplishing a mutually appropriate pace requires substantial interactional coordination and knowledge of the other, and also an acute vision. 


\section{Typifications}

Having portrayed the runner's way of seeing a training route and the particular kinds of knowledge which underpin that vision, it becomes possible to examine the 'typifications' (Schutz 1967) which are used to construct them. Just as the police whom Bittner (1967) studied survey their beat for signs of law-breaking, runners survey their route as it unfolds before them for 'trouble'. Trouble in their terms means encountering contexts, entities, or people who may injure them, or negatively impact upon their training progress and performance by forcing them to slow down, or take evasive action. Trouble then comes in various forms and these become typified as they are encountered via repetitive training in urban areas.

The language forms used in the narrative reveal the normative basis for the formation of such typifications. The tone of such language might appear excessive to the outsider, but to the serious runner all these groups constitute potential and real hazards, and the language used to categorize them mirrors this hazardous potential. Thus those on two wheels become 'idiot mad cyclists' or 'mountain bikers with attitude', children are 'deranged' and pets 'psychotic'. Hordes (of race spectators) are 'inebriated' and motor cyclists are 'illegal'. Other typified groups which are not in the narrative used in this paper include dog owners who are 'irresponsible' due to complete failure to control their animals; and teenagers who are 'dangerous' on account of their propensity to initiate unprovoked actions ranging from verbal abuse to violence.

In addition, runners become sensitized to the contexts in which there is a high propensity for such hazards to be generated. So, blind corners can be dangerous as cyclists often illegally ride around them and regular near-crashes are a routine hazard. Benign stretches of smooth summer parkland can be translated into danger zones by under-age and illegal motorcycling. Summer training routes which feature 
pubs also present runners with problems, as teenage groups frequently use their environs to 'loll' outside (Goffman 1963: 58). Dog walkers tend to favour certain pathways which runners try if possible to avoid, given the likelihood of encountering uncontrolled canine - and sometimes owners' - aggression. Under-passes constitute another risky context, in this case largely due to likely encounters with unsupervised children on foot or wheels who hurtle along with total disregard for themselves or approaching runners. Wariness is also necessary on training routes which involve driver and driving hazards. Many of the routes we run require crossing a large roundabout complex where traffic converges from multiple directions. Drivers routinely accelerate out of the roundabout towards the only available crossing point for those on foot, and the ritual utterance of 'switch on' between us alerts one other to the high degree of hazard the need for vigilance at that point in the run.

Distance runners who routinely train in a specific environment gradually construct typifications of different types of hazard and link them to sites with high risk potential. In turn those sites themselves become typified as places to avoid if possible or at least where it is necessary to be keenly alert. Habitual runners then develop over time considerable experience of dealing with these forms of contextual hazards, as Smith (1997) has also portrayed. Such hazards appear in many guises, and the authors, over many years of running experience, have for example been assailed and assaulted by persons wielding heavy handbags, house-bricks, stones, and catapults; knocked over, attacked and bitten by dogs of all sizes, as well as having grazed, cut and bruised expanses of skin thanks to the front wheels of errant cyclists, to cite but a few instances. Thus the typifications constructed are grounded in practical experience and serve a practical purpose (Garfinkel 1967), that of informing action so as to avoid 'trouble' wherever possible. 
Another set of typified categories contained within the above narrative sheds light on runners' concerns with the nature of the ground they cover. Thus, athletes of all standards tend to mark sections of route according to what training can be undertaken there, and how safe it is. Within the distance-running subculture, the term 'going' is used to categorise and portray the capabilities of terrain; thus, 'bad going' 'good going', 'hard going' and so on all constitute typifications. Bad going would describe, for example, areas where grass is long enough to conceal holes, unevenness, or tree roots. Flat, smooth roads or parkland allow the injection of pace, so constituting good going in terms of safety and performance. Hills are always hard going, demanding much extra effort to achieve momentum, but they also constitute good going in the sense that training over them is particularly demanding and thus increases stamina. Runners learn to see and comprehend the complexities of terrain and become expert at assessing what training is possible on certain sections. When routes become intimately known, athletes assess which parts to avoid, or to use for specific purposes. In addition, kinds of ground become known by both their appearance and feeling. For example, patches of boggy terrain can have an injurious impact on Achilles' tendons if run over repeatedly, as the tendon is over-stretched. As Leder (1990: 15-18) has noted, touch and seeing are for all practical purposes united in much of what constitutes lived experience. At a glance, experienced athletes not only see different kinds of ground approaching, but lodged in their kinaesthetic memory is the specific tactile sensation of an Achilles' tendon being over-extended in boggy ground.

We have portrayed in the narrative a particular active way of looking (Emmison and Smith 2000), a kind of distance-running vision. There is evidence to indicate that sociology had ignored the precise ways individuals actually undertake sport (Hargreaves 1982; Kerry and Armour 2000). In effect very little sociologically is known about how sport is done in an embodied fashion. This paper has attempted 
to remedy that lacuna in a small way by portraying the visual component of the embodied activity of training within one particular sport. The crucial functional significance of this routine and mundane component is that it underpins the effective and safe development of fitness levels necessary to participate effectively in distance running. Without such a vision, effective participation in this demanding sport would become much more problematic, if not impossible.

\section{Concluding remarks}

In this paper we have employed a novel combination of autoethnographic, ethnomethodological and visual sociological approaches to examine a particular way of seeing, underpinned by a specific subcultural stock of knowledge, used during distance-running training. Recalling Knowles and Sweetman's (2004: 7) exhortation to use the capacity of visual images to reveal the more covert, inner mechanisms of the ordinary and the taken for granted, we have sought to uncover the ways in which a specific route is seen for the practical accomplishment of running. The importance and complexity of this form of active seeing should not be underestimated for it is a central element of the interpretative activity upon which situationally appropriate behaviour depends, and a vast array of mundane activities are accomplished (Hemmings et al 2002).

The concrete, routine, everyday practices of social life are often ignored or taken for granted by some sociologists, and there is consequently a need to subject them to analysis for they constitute the very foundation of social life. Ethnomethodology has the capacity to provide social theory with the empirical analytic descriptions that can be incorporated into more abstract generalisations about social phenomena, in order better to ground those generalisations in social reality (Craig 2003). One of the great strengths of the ethnomethodological perspective is that it permits us to make strange the often taken-for-granted, mundane 'realities' of social life, and encourages 
the adoption of a more sociologically imaginative stance towards the analysis of the traditional sociological concerns of social order and social change (Hemmings et al 2002: xxiii). 


\section{References}

Allen Collinson, Jacquelyn. 2003. Running into injury time: distance running and temporality. Sociology of Sport Journal 20 (4): 331-350.

Allen Collinson, Jacquelyn and Hockey, John. 2001. Runners' tales: autoethnography, injury and narrative. Auto/Biography IX (1 \& 2): 95-106.

Becker, Howard Saul. 1974. Photography and sociology. Studies in the Anthropology of Visual Communication 1: 3-26.

Becker, Howard Saul. 1995. Visual sociology, documentary photography and photojournalism: it's (almost) all a matter of context. Visual Sociology 10: 5-14.

Benson, Douglas and Hughes, John A. 1983. The Perspective of Ethnomethodology. London: Longman.

Bittner, Egon. 1967. The Police on Skid Row. Sociological Review 2: 699-715.

Brekhus, Wayne, H. 1998. A sociology of the unmarked: redirecting our focus. Sociological Theory 16 (1): 34-51.

Brooks Gardner, Carol. 1980. Passing by: street remarks, address rights, and the urban female. Sociological Inquiry 50: 328-356.

Carr, Stephen, Francis, Mark, Rivlin, Leanne and Stone, Andrew. 1992. Public Space. Cambridge: Cambridge University Press.

Coates, Sally. 1999. Analysing the physical: an ethnomethodological study of boxing. Ethnographic Studies 4: 14-26.

Coffey, Amanda. 1999. The Ethnographic self: fieldwork and the representation of identity. London: Sage.

Craig, Robert T. 2003. Ethnomethodology's Program and Practical Inquiry. Research on Language and Social Interaction 36 (4): 471-480.

Crossley, Nick. 1995. Merleau-Ponty, the elusive body and carnal sociology. Body and Society 1 (1): 43-63.

Denison, Jim. 2002. Writing a 'true' sports story. Auto/Biography X (1 \& 2): 131-137.

Donald, J. 1995. The city, the cinema: modern spaces. In Visual Culture, edited by C. Jenks. London: Routledge.

Ellis, Carolyn. 1997. Evocative autoethnography. In Representation and the text, edited by W. Tierney and Y. Lincoln. New York: State University of New York Press.

Ellis, Carolyn and Bochner, Arthur. 2000. Autoethnography, personal narrative, reflexivity. Researcher as subject. In Handbook of qualitative research ( $2^{\text {nd }} \mathrm{ed}$.) edited by N. K. Denzin and Y. Lincoln. London: Sage.

Emmison, Michael and Smith, Philip. 2000. Researching the Visual. Images, objects, contexts and interactions in social and cultural enquiry. London: Sage. 
Garfinkel, Harold. 1963. A conception of, and experiments with, "trust" as a condition of stable concerted actions. In Motivation and social interaction, edited by $\mathrm{O}$. J. Harvey. New York: Ronald.

Garfinkel, Harold. 1967. Studies in Ethnomethodology. Englewood Cliffs, NY: Prentice Hall.

Glaser, Barney and Strauss, Anselm. 1967. The Discovery of Grounded Theory. Chicago: Aldine.

Goffman, Erving. 1963. Behaviour in public places; notes on the social organization of gatherings. New York: Free Press.

Goffman, Erving. 1974. Frame Analysis. New York, NY: Harper.

Goode, David. 1994. A World without words: The social construction of children born deaf and blind. Philadelphia: Temple University Press.

Goodwin, Charles and Harness Goodwin, Marjorie. 1998. Seeing as situated activity: formulating planes. In Cognition and Communication at Work, edited by Y. Engeström and D. Middleton. Cambridge: Cambridge University Press.

Hargreaves, Jenny, ed. 1982. Sport, Culture and Ideology. London: Routledge \& Kegan Paul.

Harper, Douglas. 2004. Wednesday-Night Bowling. Reflections on cultures of a rural working class. In Picturing the Social Landscape. Visual methods and the sociological imagination, edited by C. Knowles and P. Sweetman. London: Routledge.

Harrison, Barbara. 2002. Seeing health and illness worlds - using visual methodologies in a sociology of health and illness: a methodological review. Sociology of Health \& IIIness 24 (6): 856-872.

Hayano, David M. 1979. Auto-ethnography: Paradigms, problems and prospects. Human Organization 38 (1): 99-104.

Hayano, David M. 1982. Poker Faces: The life and work of professional card players. Berkeley: University of California Press.

Hemmings, Sue, Silva, Elizabeth B. and Thompson, Kenneth. 2002. Accounting for the everyday. In Understanding Everyday Life, edited by T. Bennett and D. Watson. Oxford: Open University/Blackwell.

Heritage, John C. 1989. Current developments in conversation analysis. In Conversation: An interdisciplinary approach, edited by D. Roger and P. Bull. Avon, Hampshire: Multilingual Matters.

Hockey, John. 2005. Injured distance runners: a case of identity work as self-help. Sociology of Sport Journal 21 (1): 38-58.

Howe, P. David. 2004. Sport, Professionalism and Pain: ethnographies of injury and risk. London: Routledge. 
Kerry, Daniel S. and Armour, Kathleen M. 2000. Sports sciences and the promise of phenomenology: Philosophy, method and insight. Quest 52 (1) :1-17.

Kew, Francis. 1986. Playing the game: an ethnomethodological perspective. International Review for Sociology of Sport 21 (4): 305-321.

Knowles, Caroline and Sweetman, Paul. 2004. Introduction. In Picturing the Social Landscape: Visual methods and the sociological imagination, edited by C. Knowles and P. Sweetman, P. London: Routledge.

Leder, Drew. 1990. The Absent Body. Chicago: University of Chicago Press.

Lofland, Lyn H. 1973. A World of Strangers. New York: Basic Books.

Lutz, Ronald. 1991. Careers in running: individual needs and social organization. International Review for the Sociology of Sport 26 (3): 155-174.

Lynch, Michael E, Livingston, Eric and Garfinkel, Harold. 1983. Temporal order in laboratory work. In Science observed: Perspectives on the social study of science, edited by K. Knorr Cetina and M. Mulkay. London: Sage.

Okely, Judith. 1996. Own or Other Culture. London: Routledge.

Pink, Sarah. 2001. Doing Visual Ethnography: images, media and representation in research. London: Sage.

Psathas, George. 1979. Organizational features of direction maps. In Everyday Language: Studies in ethnomethodology, edited by G. Psathas. New York: Irvington.

Reed-Danahay, Deborah, ed. and comp. 1997. Auto/Ethnography. Oxford: Berg.

Rinehart, Robert. 1998. Born-again sport: ethics in biographical research. In Sport and Postmodern Times, edited by G. Rail. Albany, NY: State University of New York Press.

Rose, Gillian. 1993. Feminism and Geography: The limits of geographical knowledge. Cambridge: Polity Press.

Rustin, Michael. 1993. Ethnomethodology. In Debates in Sociology, edited by D. Morgan and L. Stanley. Manchester: Manchester University Press.

Ryave, A Lincoln and Schenkein, James N. 1975. Notes on the art of walking. In Ethnomethodology: Selected readings, edited by R. Turner. Harmondsworth: Penguin.

Sanjek, Roger, ed. 1990. Fieldnotes: The making of anthropology. Ithaca, NY: Cornell University Press.

Schutz, Alfred. 1967. The Phenomenology of the Social World. Translated by G. Walsh and F. Lehnert. Evanston, ILL: Northwestern University Press.

Segrave, Jenny O. 2000. Sport as escape. Journal of Sport and Social Issues 24: 61-77. 
Sharrock, Wesley W. and Anderson, Digby C. 1979. Directional hospital signs as sociological data. Information Design Journal 1 (2): 81-94.

Smith, Greg. 1997. Incivil attention and everyday tolerance: Vicissitudes of exercising in public places. Perspectives on Social Problems 9: 59-79.

Snow, David A., Burke, E. Rochford Jr., Worden, Steven K. and Benford, Robert D. 1986. Frame alignment processes, micromobilization, and movement participation. American Sociological Review 51: 464-481.

Sparkes, Andrew. 2000. Autoethnography and narratives of the self: Reflections on criteria in action. Sociology of Sport Journal 17 (1): 21-43.

Spence, Jo. 1986. Putting Myself in the Picture: a personal, political and photographic autobiography. London: Camden Press.

Sudnow, David. 1972. Temporal parameters of interpersonal observation. In Studies in Social Interaction, edited by D. Sudnow. New York: Free Press.

Sudnow, David. 1978. Ways of the Hand. Cambridge, MA: Harvard University Press.

van Maanen, John, ed. 1995. Representation in Ethnography. London: Sage.

Woodward, R. 1998. It's a man's life: soldiers, masculinity and the countryside. Gender, Place and Culture 5 (3): 277-300. 


\section{List of figures/photographs}

Figure 1. Park gates, woman with dog

Figure 2. Pathway to subway

Figure 3. Entrance to subway

Figure 4. Slope and tennis courts

Figure 5. Marshy ground by clump of trees

Figure 6. Runner with low-hanging branches

Figure 7. Line of trees and shade

Figure 8. Basketball court

Figure 9. Flat, smooth parkland for ' intervals'

Figure 10. Speeding car on roundabout

Figure 11. Tarmac-covered roots 
Figure 1. Park gates, woman with dog

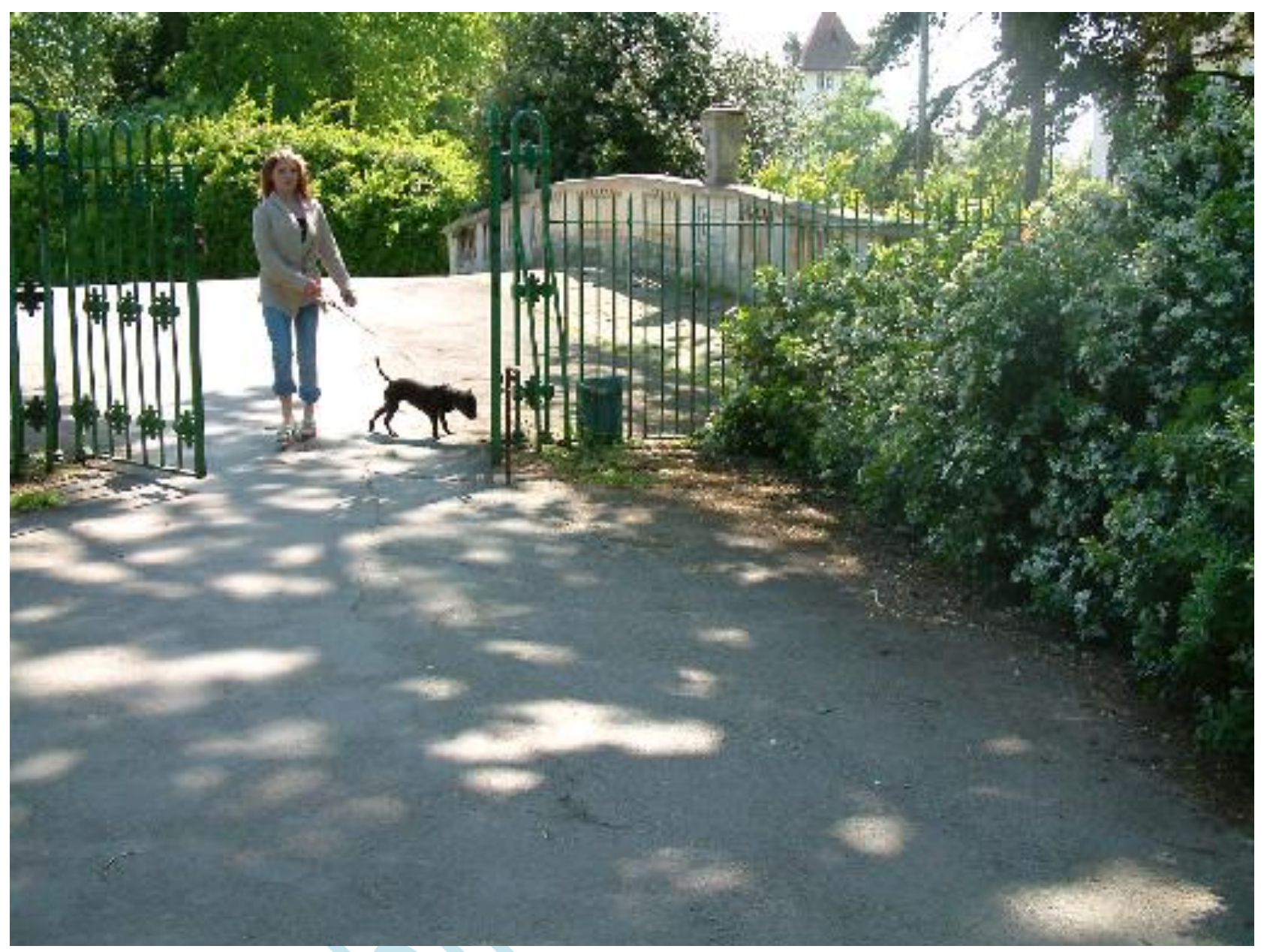


Figure 2. Pathway to subway

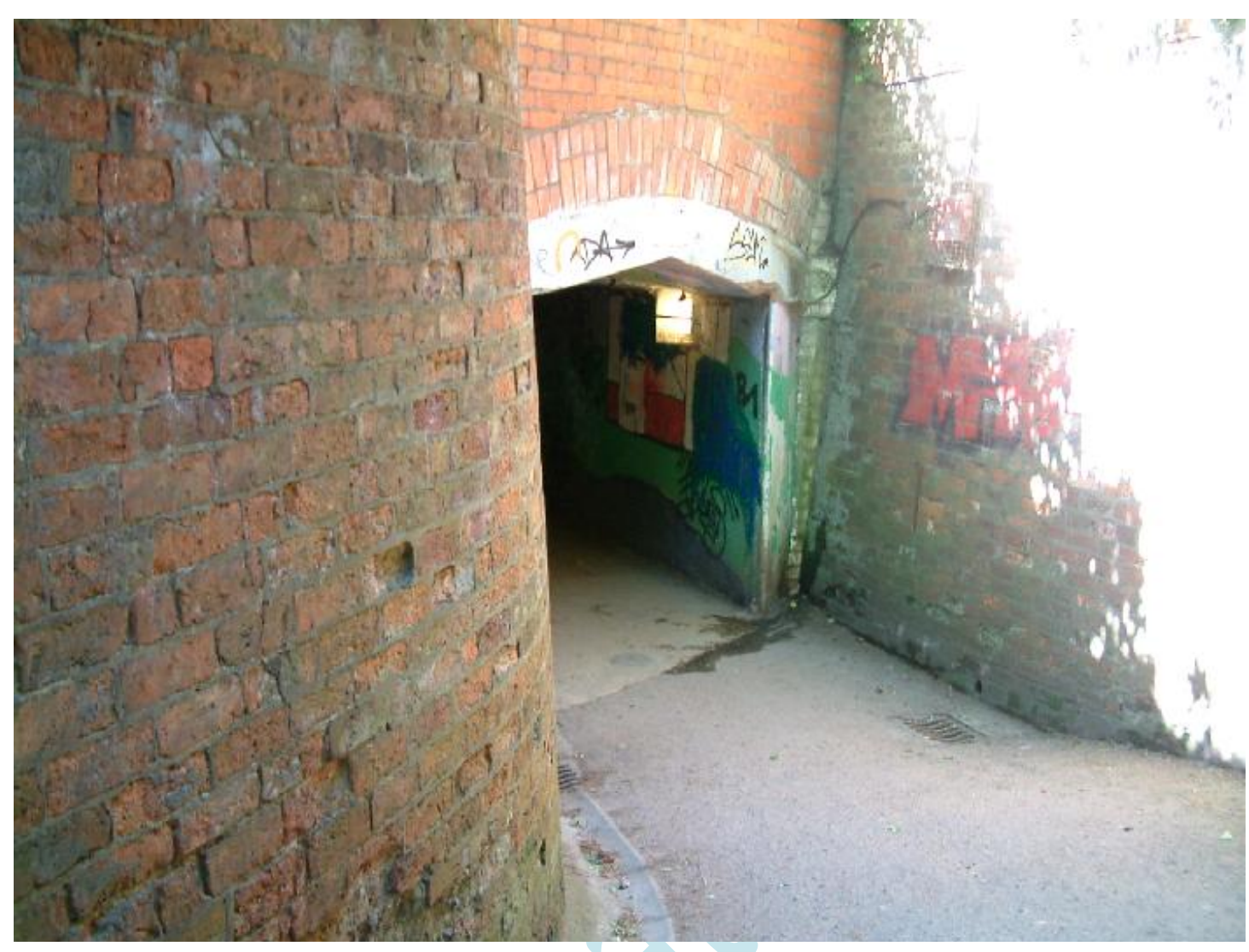


Figure 3. Entrance to subway

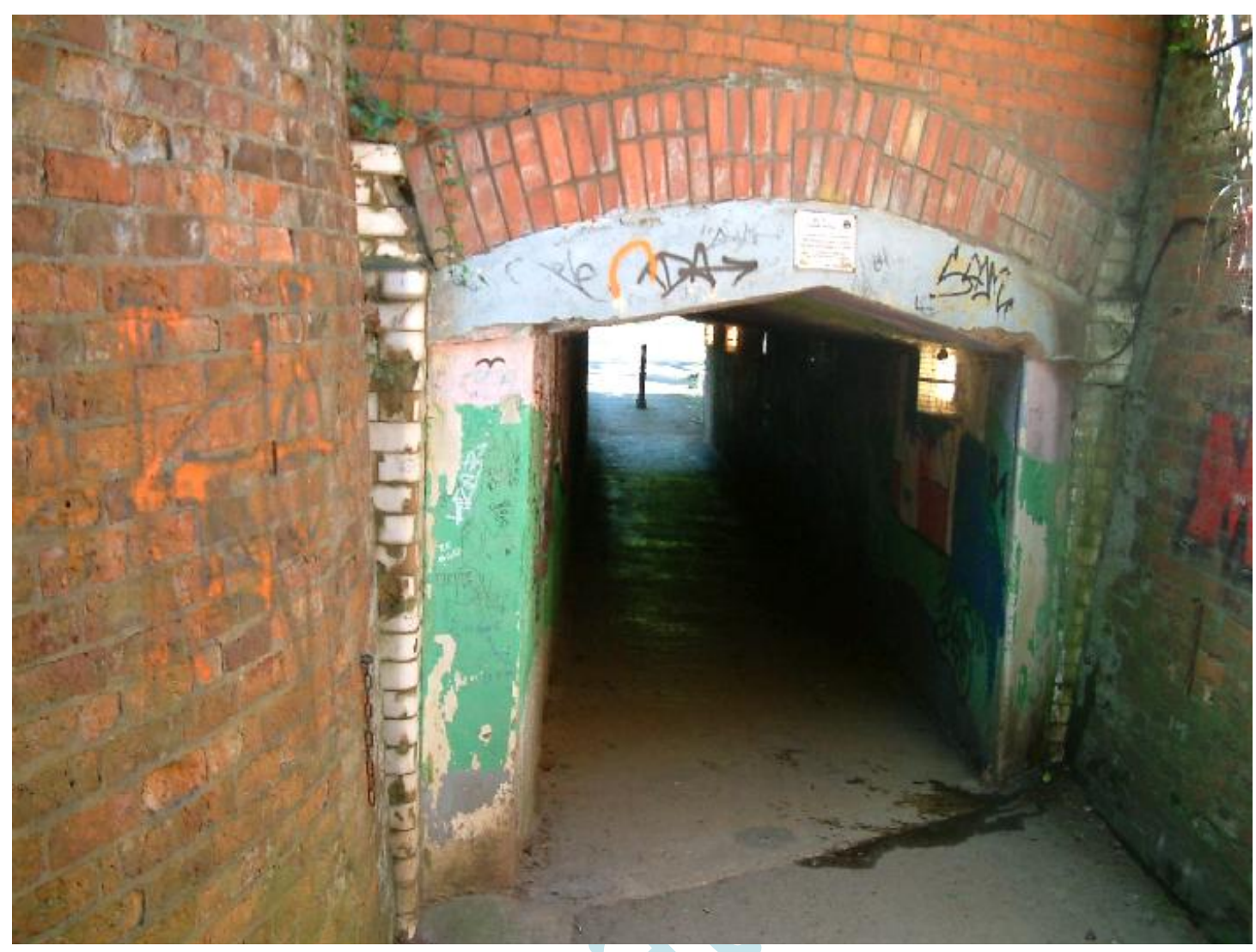


Figure 4. Slope and tennis courts

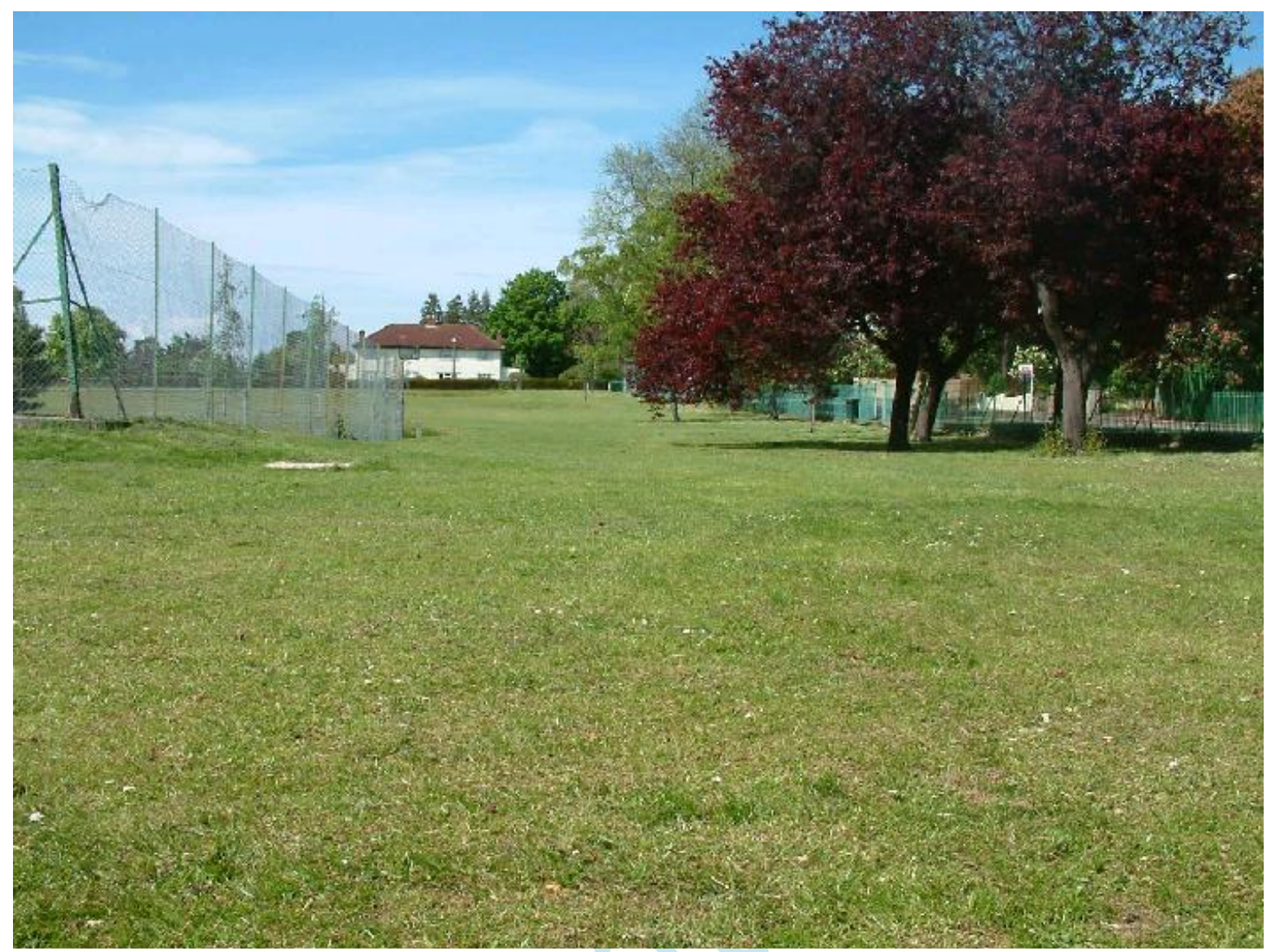


Figure 5. Marshy ground by clump of trees

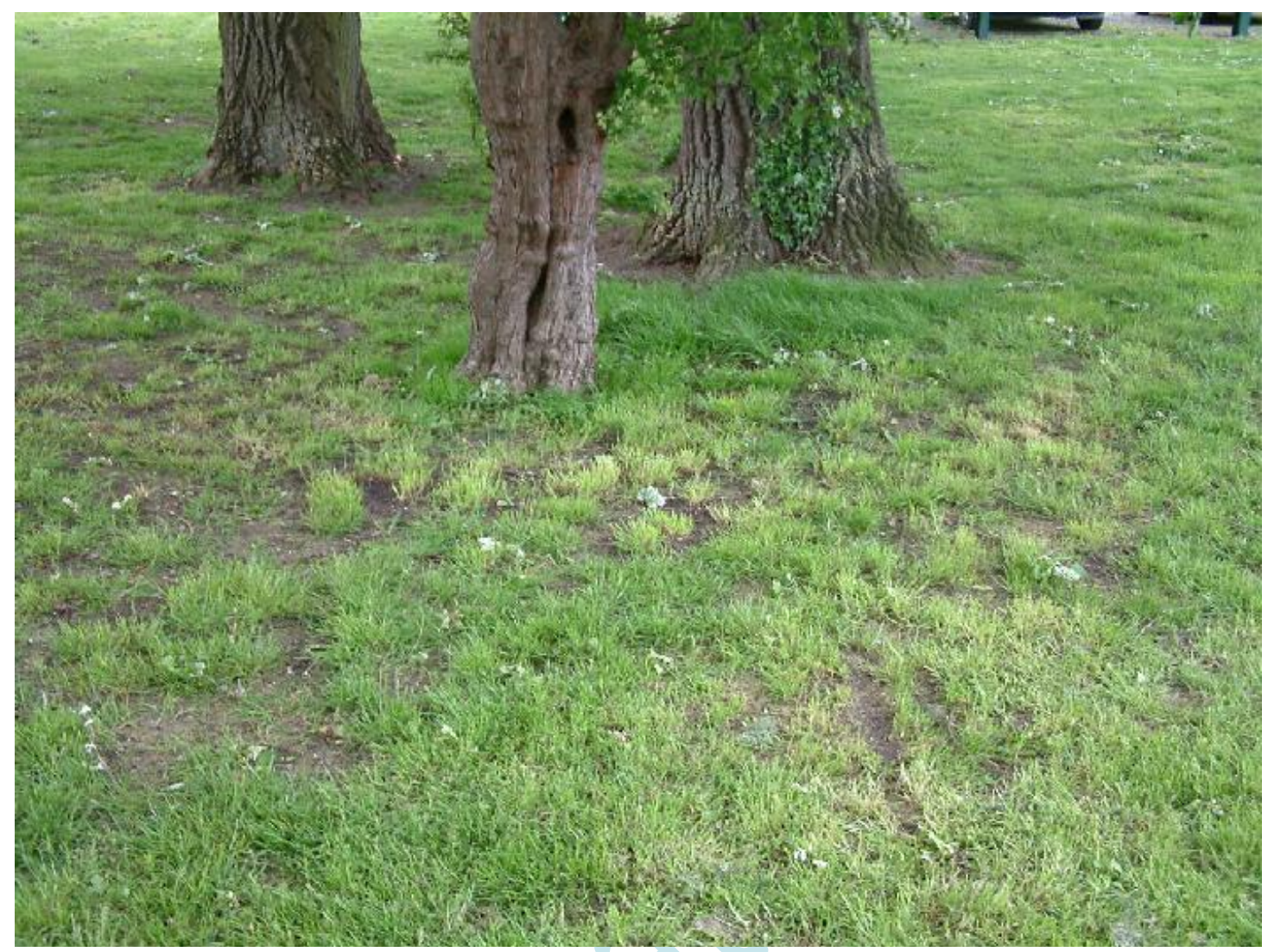


Figure 6. Runner with low-hanging branches

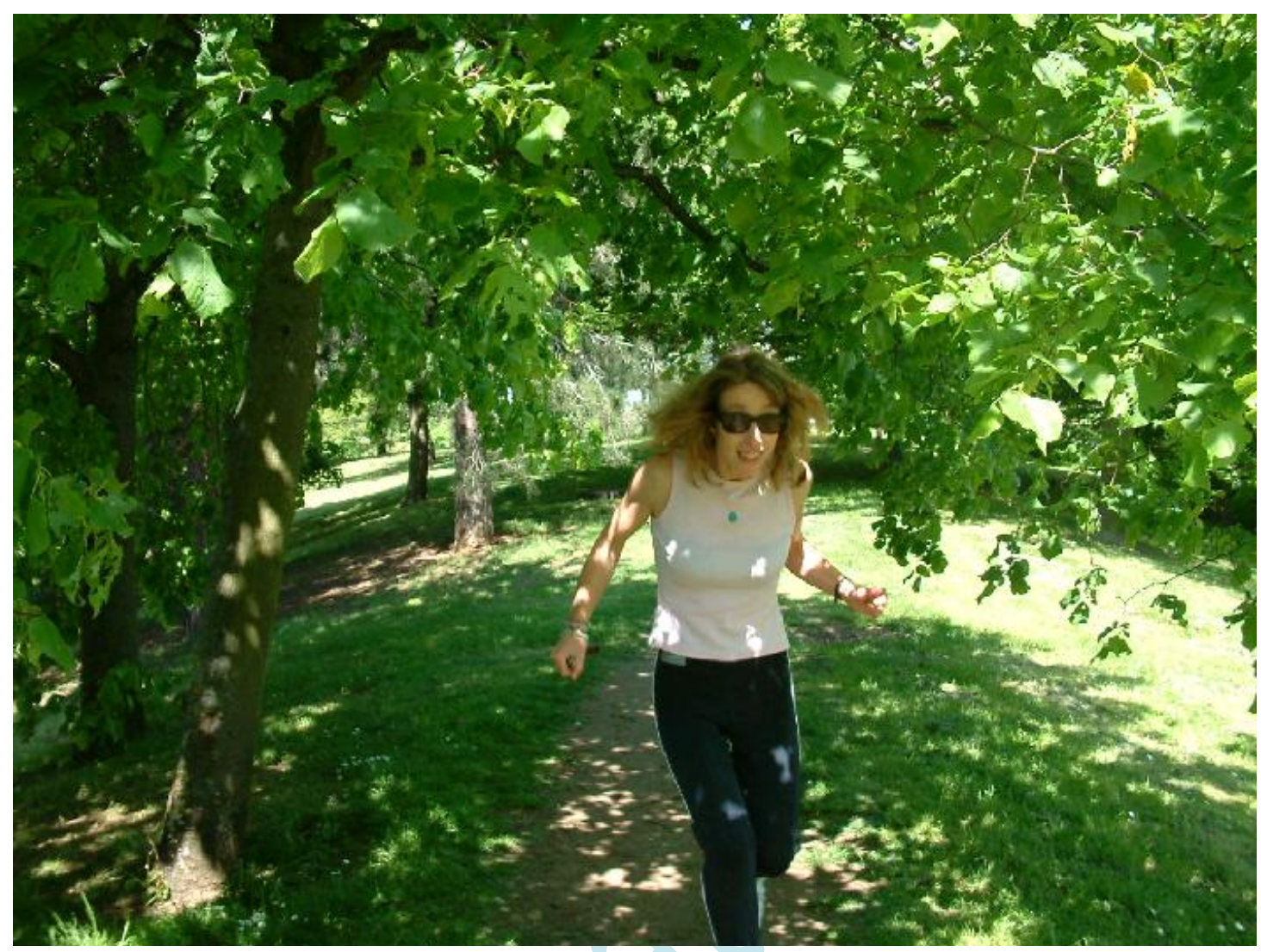


Figure 7. Line of trees and shade

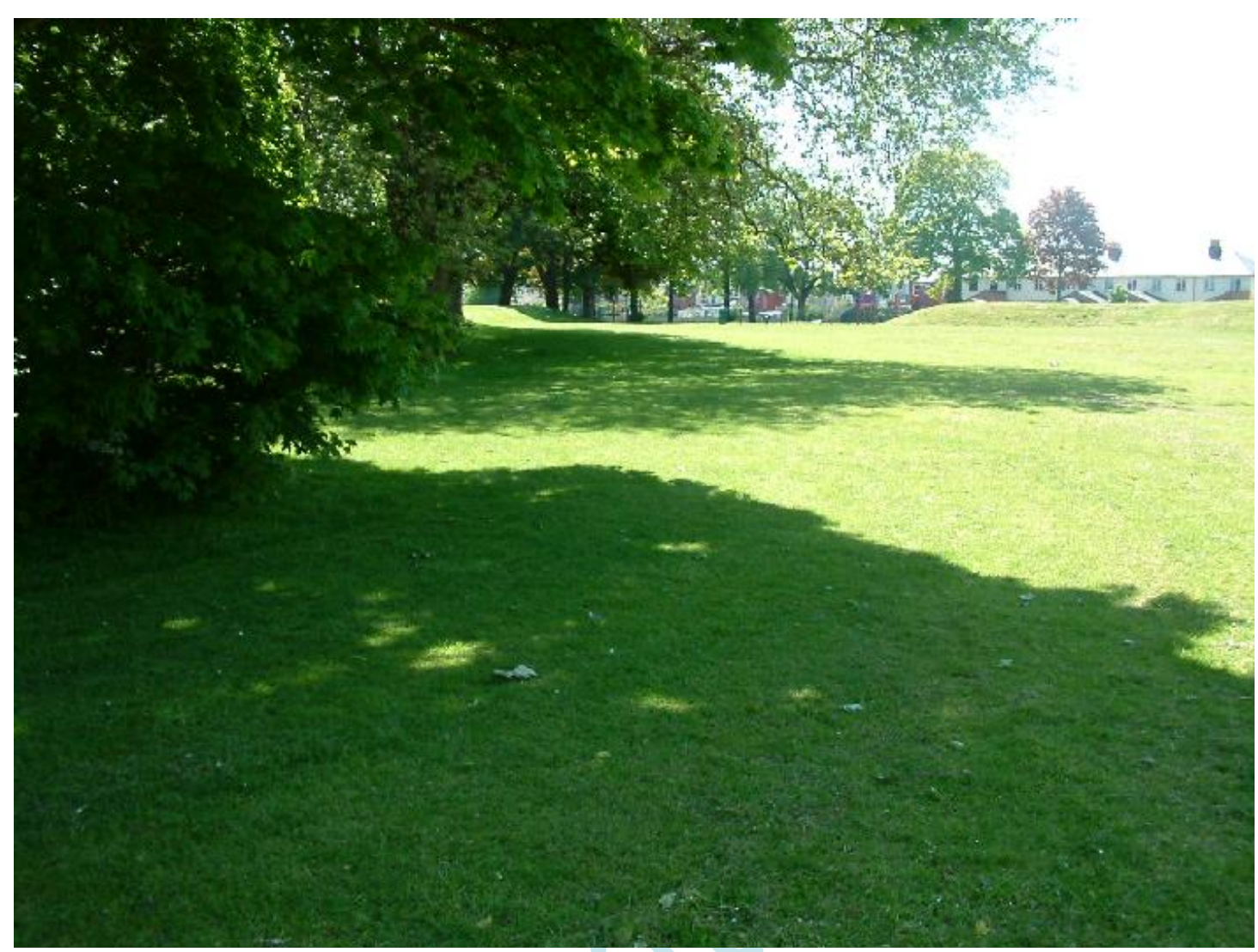


Figure 8. Basketball court

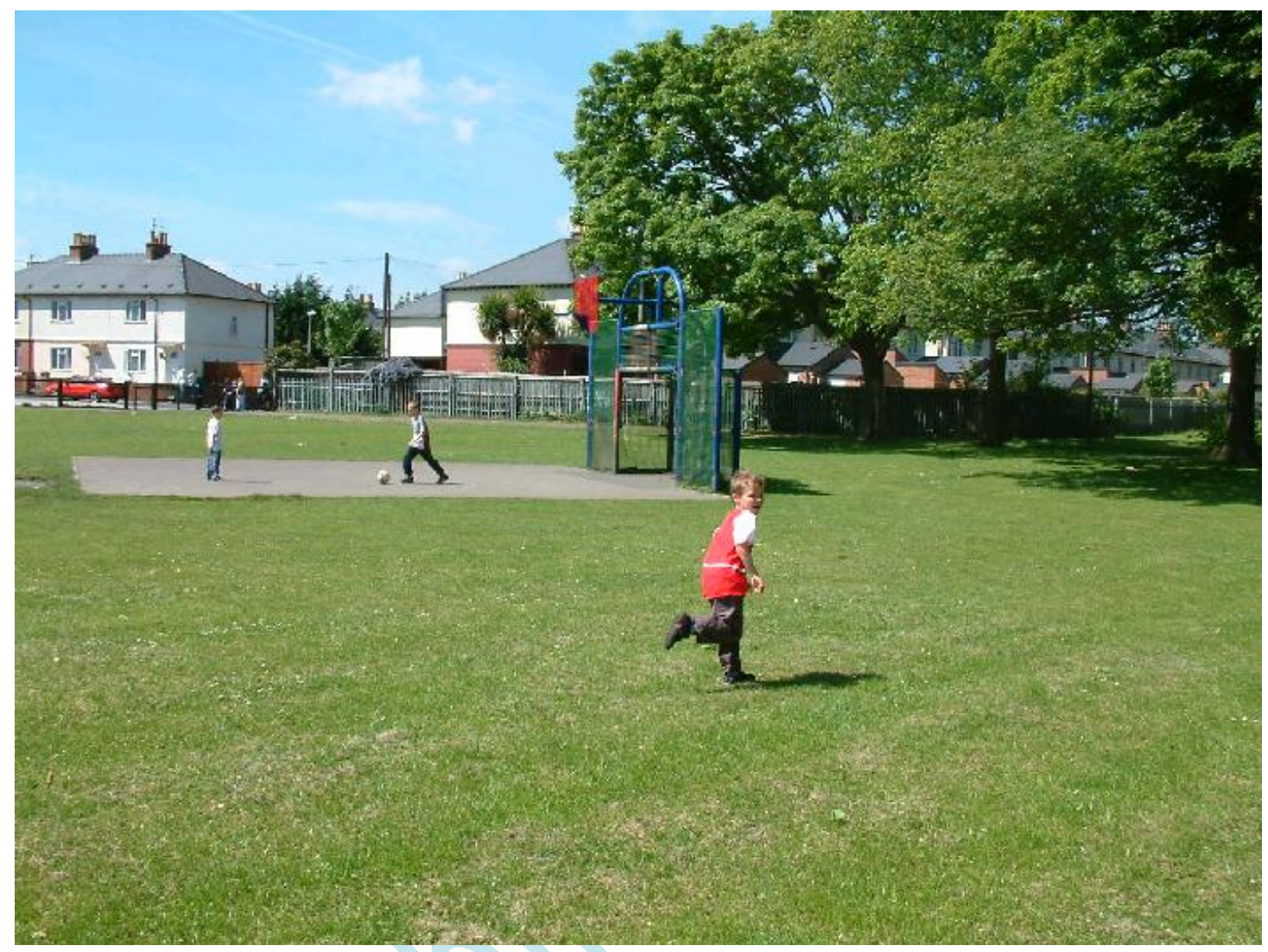


Figure 9. Flat, smooth parkland for ' intervals'

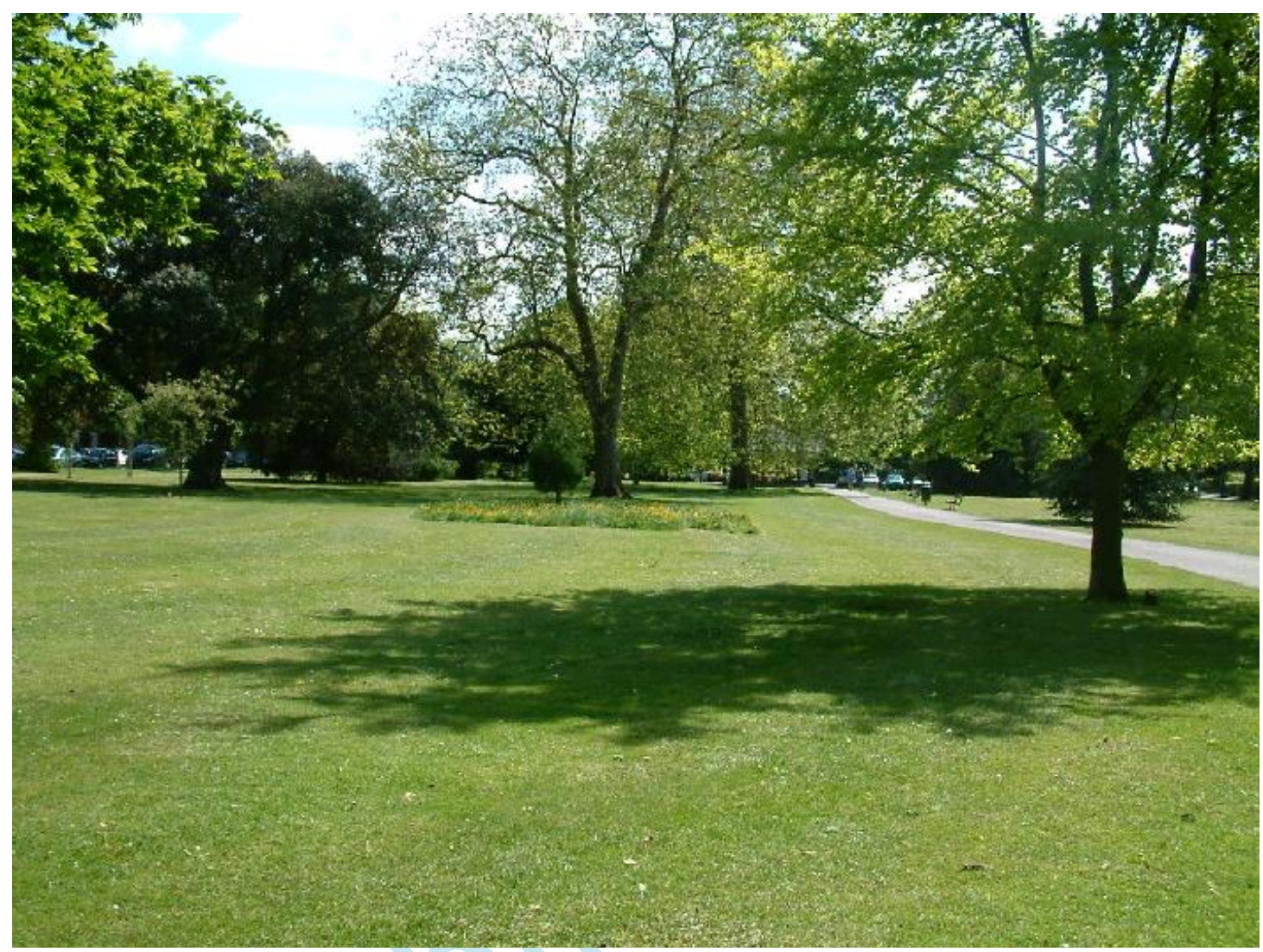


Figure 10. Speeding car on roundabout
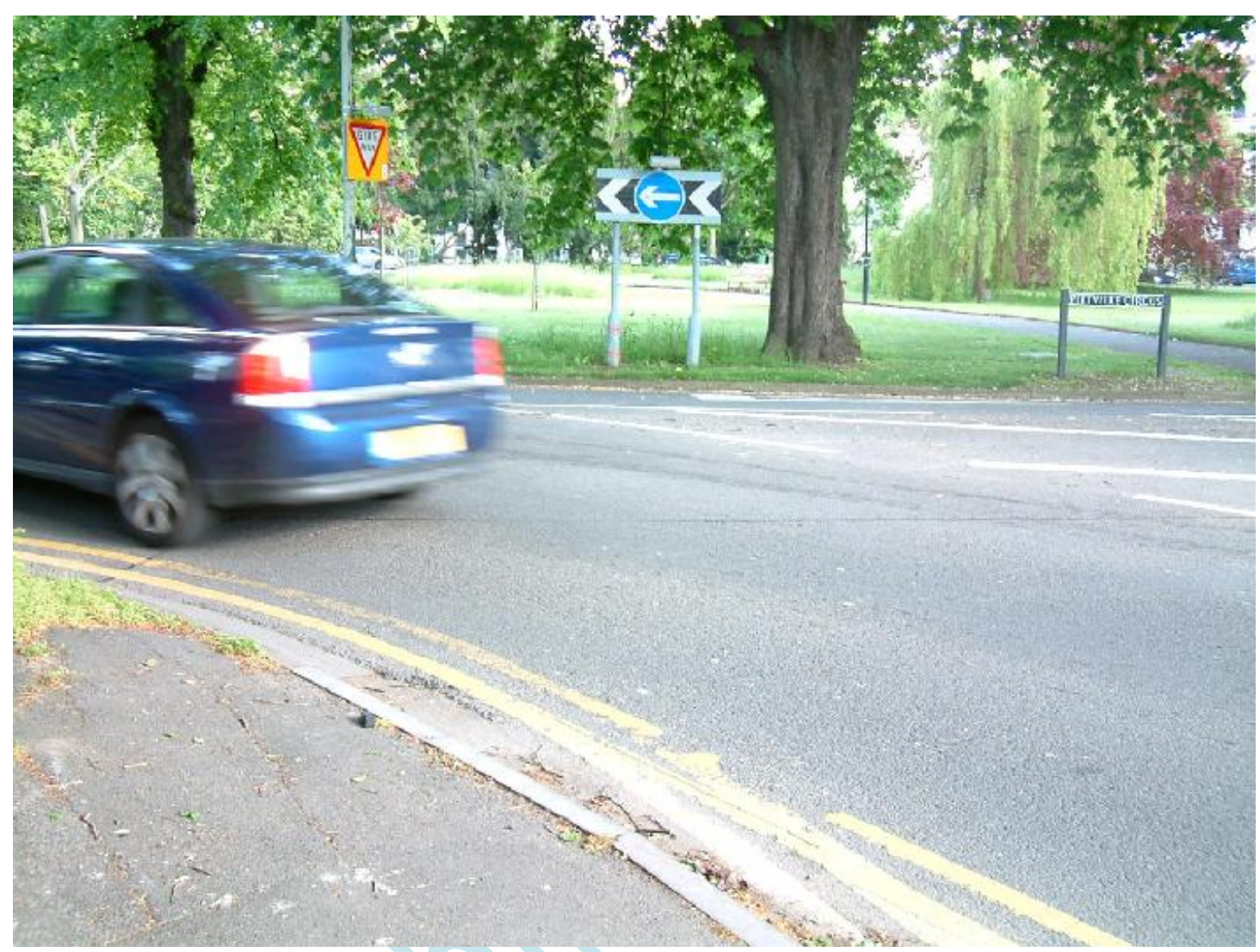
Figure 11. Tarmac-covered roots

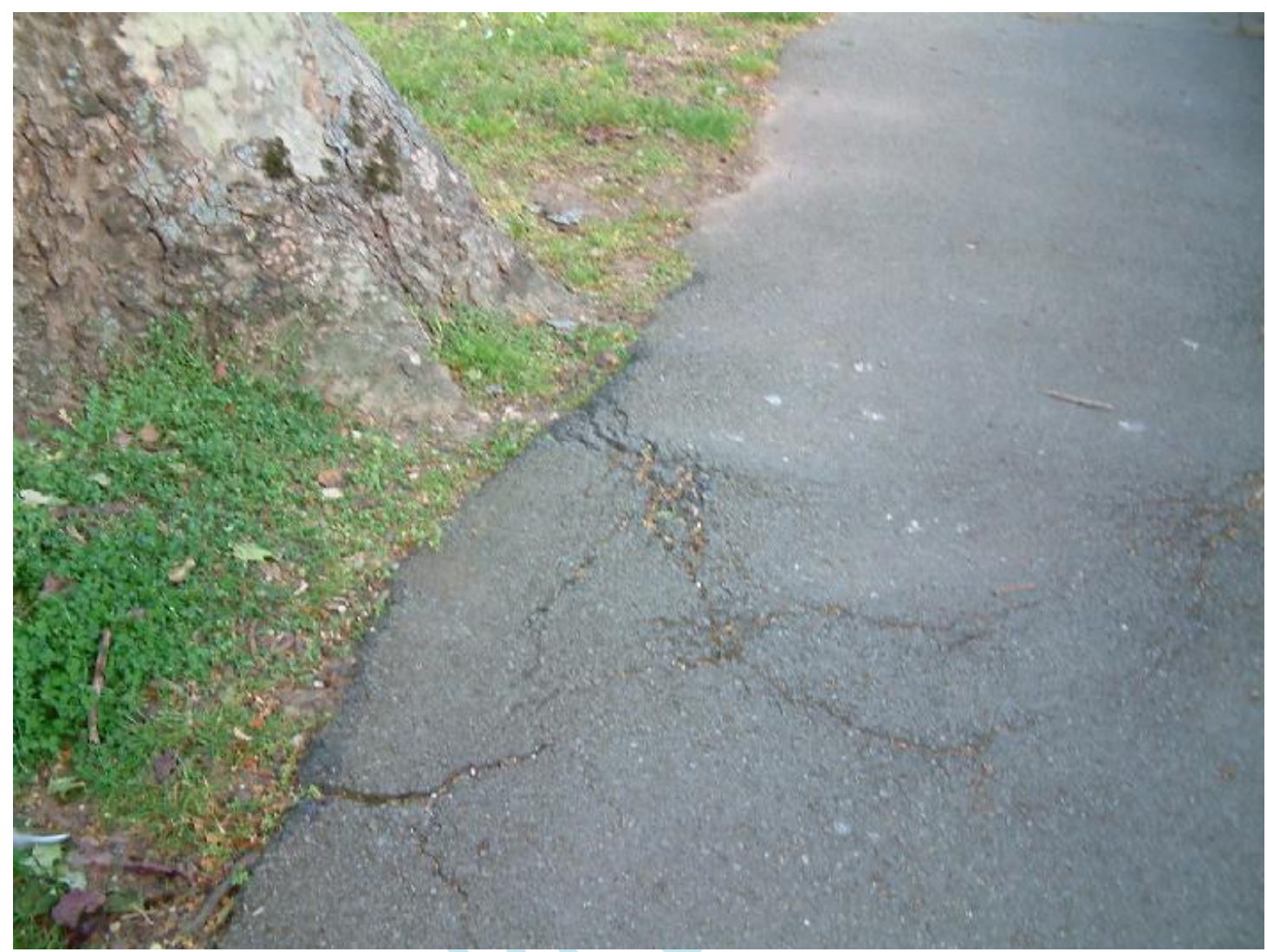

